\title{
Correspondence
}

\section{Guidelines on formulation}

DeAR SIR

There is considerable scope for disagreement in psychiatry: about diagnosis, aetiology and even the very nature of psychiatric disorders. In fact we find this is one of psychiatry's great attractions. It is presumably out of this large area of debate that the process of formulation evolved; a device whereby the features of an individual case can be discussed and evaluated in order to describe a series of probabilities which will guide the management. This seems to be an admirably flexible way to deal with the complexities and uncertainties of psychiatric problems and it is, therefore, both sensible and necessary to focus attention on this skill in the qualifying examination.

We are concerned about the reports we have received from candidates about the various ways in which this skill is currently being assessed by some examiners. Comments such as 'This is a summary, not a formulation ...' 'The formulation does not include management ...' or 'Give us your formulation in two sentences, please ...' are not only unsettling, but appear to us to reflect an unnecessarily rigid point of view, particularly since the main function of the formulation is to avoid a dogmatic and inflexible approach to psychiatry. One of us has made videotapes of 15 'mock' clinical examinations and has been impressed by the lack of consistency in what the examiners regard as a 'formulation'.

In order to avoid a sterile debate taking place during the examination concerning the nature of a formulation, we would like flexible guidelines provided for both examiners and candidates in order to facilitate discussion about the patient and his/her problem which is, after all, the purpose of a clinical examination.

We have appended a format we use when teaching our students and suggest that this could be used as the starting point for debate.

\section{St Bartholomew's Hospital London ECl}

Institute of Psychiatry DigBY TANTAM

\section{London SES}

\section{Guidelines on formulating a case for the MRCPsych Examination}

The formulation represents your summing up of a case and its structure helps you in organizing your thoughts around the case's important aspects. It is the next step in understanding and evaluation after the basic history has been obtained.
Some general principles should be borne in mind. The formulation is about an individual case and general psychiatric knowledge should be introduced only in so far as it is relevant to the particular case.-It should not sound like a textbook account of a psychiatric disorder as manifest in an individual. Although there is a fairly well accepted structure to the formulation, you need to be flexible in its use and to adapt it to the particular problems presented by the patient. For example, if the patient is unable to give you a good account of the history and is unable to elaborate on the content of his thinking, then more attention will need to be paid to the mental state examination and much of the discussion on management will be devoted to means of obtaining further information. The formulation should bring the patient to life as an individual rather than present the patient as an example of a particular psychiatric disorder.

You should be able to present your formulation in about 10 minutes but you should also be able to contract or expand it, to 5 minutes or 15 minutes for example, if the occasion demands.

\section{The structure of the formulation}

\section{Introductory comments}

It is customary to introduce some of the salient socio-demographic features of the patient in the first sentence, e.g. Mrs J. is a 40-year-old lady, divorced for 4 years, with 2 children, who works as a legal secretary and lives with her mother.

If you have experienced any difficulties in taking a history from the patient you could mention this next. The examiners will then know that they must take this into account for the remainder of the presentation-e.g. there were major difficulties in taking a history from Mrs J. as her attention was very limited and she was very unforthcoming in response to simple questions; $\mathrm{Mr} \mathrm{K}$. refused to answer questions on a number of subjects raised during the interview, e.g. his marriage, forensic history.

\section{The presenting problem}

This must be brief, usually a paragraph or so. State the main problems without any irrelevant detail. It is essential to make the chronology clear. Mention briefly how the patient's life has been affected by the problems. Obvious events closely related in time to the onset or exacerbation of symptoms could be mentioned here, as could a brief reference to treatments in the past.

An account of the important findings in the patient's mental state should then be given. The amount of detail you should provide will vary with the case. You might at this point only label the psychopathological features found (e.g. third party hallucinations, delusions of passivity) and reserve a more detailed discussion of the content for the differential diagnosis later. If you give details at both stages in the formulation you might find that you are wasting time with needless repetition.

\section{Differential diagnosis}

If there is little doubt about the diagnosis, say so-also say why. You will usually mention a few possible differential diagnoses and be able to dismiss them easily. 
If the diagnosis is not clear then you will need to embark on a more careful discussion of the possibilities in order of likelihood. Beware of giving a list of difierential diagnoses that encompasses all of psychiatry. Think twice before offering more than 3 or 4 . The differential diagnosis tests your ability to make a discriminating clinical judgement.

Some diagnoses are not mutually exclusive, e.g. a depressive illness in a person with an obsessional personality complicated by a drinking problem.

List the possibilities first. Then for each possible diagnosis you must marshal the evidence for and against. This will usually be drawn from the descriptive psychopathology and course of the illness. You may at this point wish to introduce more details of the mental state examination, e.g. the content of delusions in differentiating schizophrenia from a depressive psychosis.

End the discussion with a concluding remark about the most likely diagnosis or if you believe that this is impossible at this stage, about the major possibilities.

\section{Aetiological factors}

Keeping in mind a scheme based on two fundamental dimensions may be of help here.

(a) Time: (i) Remote events; (ii) Intermediate events; and (iii) Recent and precipitating events.

(b) Type of factor: (i) Physical (including genetic, constitutional, physical illness, drugs, alcohol, etc.); (ii) Psychological (individua psychodynamics, personality, etc.); and (iii) Socio-cultural (social supports, employment, etc.).

Remote events include developmental factors, birth trauma, etc. as well as important events (e.g. parental death, serious illness).

Intermediate events will be mainly concerned with the patient's personality and the ways in which he copes with life. Think whether you are able to make a comment about the patient's personality and any problems in this area-this may help to bring the case to life. Think perhaps about the way he has coped with stress, losses, other people, work, the law, etc. Have there been ongoing tensions in the patient's life which when added to by a recent event have led to his undoing? Make it clear, however, that as you only have the patient's account, your impressions will need to be confirmed by questioning other informants. Concentrate on objective evidence in your assessment.

Recent events-look for precipitating factors associated in time with the onset or exacerbation of symptoms. Be careful before ascribing causal significance to these and enquire whether they may be a consequence rather than a cause of the illness, e.g. losing a job because of depression rather than depression being the result of losing a job. Think about physical, psychological and social factors.

By considering all of these factors you may find that you are able to weave a plausible narrative describing how and why the patient became ill at this particular time. You may feel inclined to include a psychodynamic formulation. Think twice before doing this. If you decide to go ahead, you are probably best advised to avoid jargon here and to keep it at a simple level supportable by the facts of the case.

Remember also to preserve a balance in discussing aetiologica factors. Do not concentrate unduly on one just because it is particularly bizarre or interesting or because you have just read a paper about it.

\section{Management}

This might be divided as follows: (i) Further investigation; (ii) Immediate management plans; and (iii) Long-term management plans.

(i) Further investigations: These will almost always include an interview with at least one informant and a review of previous case notes. Say who the best informant would be and what information you would be particularly concerned to obtain (e.g. an account of the patient's premorbid personality). Say also what information you would wish to obtain from the case notes (e.g. a record of courses of antidepressants and an insurance that they were prescribed in adequate dosages). You may wish to speak to the GP or the patient's employer.

You will then discuss other relevant investigations and be able to justify them all, including psychometry. It is probably unnecessary to list routine investigations unless they are of special importance for the case. Do not forget that there are important sources of information which do not derive from blood, urine and the brain. Nursing observations, a social worker's report and occupational therapy assessments may have a crucial influence on your final diagnostic formulation and management plans. A family interview may be useful, as may school reports and employers' references.

(ii) Immediate management plans: Before you rush into recommending a drug treatment or psychotherapy, think about some preliminary issues. How easy is it to make a rapport with the patient and what is the likelihood of forming a therapeutic alliance at this stage? If there is a problem, discuss how you would manage it. Should the patient be an in-patient, out-patient or not a patient at all? It may be relevant to discuss the use of a compulsory order here.

If in-patient care is appropriate, what contributions would you expect from the nursing staff, social workers and occupational therapists? What instructions would you give them concerning a suicidal or violent patient for example?

If you prescribe medication, you might mention how you would monitor its effects and how likely you think it is that the patient will respond. The question of compliance will be relevant.

(iii) Long-term management plans: You could think again in terms of physical, psychological and social interventions. For example, how long would you wish to give maintenance phenothiazines? What factors would influence your decision? How frequent and for how long should contact with the patient be after discharge?

What sort of psychological help will he need-supportive psychotherapy, formal psychotherapy or brief interviews to assess progress? What issues might need to be worked on? Might specialist services be required? To what extent would you involve the family or others in the patient's treatment? Is rehabilitation necessary? If it is, how would this be done? What sorts of social provisions might need to be made, e.g. a hostel, invalidity benefit, social club, etc. How can the patient's social environment be constructed so as to reduce the risk of later relapse? Not infrequently relatively 'trivial' measures may make a substantial impact on the patient's quality of life, e.g. new spectacles, a hearing aid, enrolling in an adult literacy class.

In general, try not to lose sight of the individual and his particular needs when discussing the management. The treatment needs to be tailored to the patient.

\section{Prognosis}

The commonest error here is to give a prognosis for the illness 
entity in general rather than for the individual patient with the illness, e.g. 'the prognosis of schizophrenia depends on ...' rather than 'the good prognostic features in this patient are ...'

There are a number of elements which determine the prognosis and which you might bring in. You will often find a mixture of good and bad prognostic features which you will need to balance up in arriving at your final judgement.

You might consider the following:

(a) Known prognostic features of the illness as applied to this particular patient, e.g. affective 'colouring' in a schizophrenic illness, acute onset, etc.

(b) The course of the illness-if it is already chronic it is likely to remain so.

(c) Response to treatment in the past.

(d) Co-operation with treatment in the past and now.

(c) Premorbid adjustment.

(f) Social supports and influences.

(g) Motivation to improve.

(h) The availability of special treatment facilities.

It may be helpful to divide the prognosis into the short term and long term, e.g. the patient may have a good prognosis for recovery from the current episode but be at high risk for relapse in the future.

\section{Staff communication}

Dear Sir

Having read the account of the staff support system at Hill End Adolescent Unit (Bulletin, July 1982, 6, 117-19) I very much doubt whether the desired open communication can be fostered in such a culture. Staff meetings in which the use of first names is compulsory, in which statements are prohibited which are not ' $I$ ' statements, and in which there are rules which forbid conversation about absent colleagues and patients, strike me as being every bit as defensive, restricted in communication, and tyrannical as the hierarchical system which the authors purport to eschew.

The danger of such groups is that the members are forced into a pattern of pseudo-open communication in order to conform to rigid group norms; thus more is avoided than is dealt with, tension is greater, and there are repercussions elsewhere in the system.

Central Middlesex Hospital

Harold L. BeHR

London NW10

\section{Psychiatric experts and expertise-will the real expert please stand up?}

\section{Dear Sir}

The article by the barrister, Diana Brahams, on 'Psychiatric testimony-Who can give it and when?' (Bulletin, July 1982, 6, 121-22) raises a number of interesting points as to who is best qualified to give evidence on problems of mental and behavioural abnormality.

In the case cited by Mrs Brahams (Mackenny and Pinfold) I would accept that the qualifications of the psychologist (who was not allowed by the trial judge to give evidence) could be called into question, but I wonder how the matter might have been resolved if the psychologist involved had been a properly trained clinical psychologist -employed by the National Health Service-who had experience in diagnosis and treatment of mental disorder, and who was conversant with preparing reports for solicitors as well as in giving expert evidence in courts, be they at Magistrate, County or higher courts.

My own experience in legal matters indicates that clinical psychologists not only provide reports for solicitors, but that in many instances solicitors (as well as barristers) specifically request a psychologist's report in preference to or, in conjunction with a medical or psychiatric report. Moreover, examples of cases where psychologists are requested to attend Court to give evidence include Compensation (brain damage, psychological effects of personal injury); Matrimonial (access, custody, care proceedings); Juvenile and Adult Crime (burglary, damage to property, murder, rape, theft), not to mention acting in an advisory capacity to the legal profession.

I can recall an occasion (the first time I gave evidence) when the 'other side' in a compensation case objected to my report-and presumably me as well-being granted 'expert' status. The learned judge, after listening to counsel's objections, took a few moments before giving his decision on my report, namely-'Oh nonsense, put it with all the rest!' (i.e. the medical reports). Despite my nod of approval at the time, I later realized that His Lordship had poured equal scorn on both the so called medical and psychological expertise. A fuller account of this incident has been reported elsewhere (Kaufman, 1980).

A few months ago I was asked by another judge if I was qualified to give an opinion on a man's state of mind concerning whether or not he was suffering from an 'abnormality of mind' at the time he took money belonging to his firm, because, after all, I was 'not a psychiatrist'. My reply was that not only did I think I was qualified to offer my opinion, but that in my experience as well as that of many of my colleagues, we are often referred cases (by psychiatrists) for our diagnostic assistance. I also pointed out that in one area of clinical psychology specialization, the task is one of deciding if an abnormality in behaviour or deterioration in intellectual function is due to an organic as opposed to a non-organic cause and, in some instances, to help pinpoint the site of the lesion in diagnoses of cerebral deficit.

These explanations appeared to satisfy the learned judge and no more was said of my qualifications to give evidence as a clinical psychologist or, to give evidence on the matters in question, even by the very thorough opposing barrister appearing for the prosecution.

I can cite other instances where I have been asked to 